\title{
The Added Prognostic Value of Preoperative Dynamic Contrast-Enhanced MRI Histogram Analysis in Patients with Glioblastoma: Analysis of Overall and Progression-Free Survival
}

\author{
(D)Y.S. Choi, D.W. Kim, S.-K. Lee, J.H. Chang, S.-G. Kang, E.H. Kim, S.H. Kim, T.H. Rim, and S.S. Ahn
}

\begin{abstract}
BACKGROUND AND PURPOSE: The prognostic value of dynamic contrast-enhanced MR imaging in patients with glioblastoma is controversial. We investigated the added prognostic value of dynamic contrast-enhanced MR imaging to clinical parameters and molecular biomarkers in patients with glioblastoma by using histogram analysis.
\end{abstract}

MATERIALS AND METHODS: This retrospective study consisted of 61 patients who underwent preoperative dynamic contrast-enhanced MR imaging for glioblastoma. The histogram parameters of dynamic contrast-enhanced MR imaging, including volume transfer constant, extravascular extracellular volume fraction, and plasma volume fraction, were calculated from entire enhancing tumors. Univariate analyses for overall survival and progression-free survival were performed with preoperative clinical and dynamic contrast-enhanced MR imaging parameters and postoperative molecular biomarkers. Multivariate Cox regression was performed to build pre- and postoperative models for overall survival and progression-free survival. The performance of models was assessed by calculating the Harrell concordance index.

RESULTS: In univariate analysis, patients with higher volume transfer constant and extravascular extracellular volume fraction values showed worse overall survival and progression-free survival, whereas plasma volume fraction showed no significant correlation. In multivariate analyses for overall survival, the fifth percentile value of volume transfer constant and kurtosis of extravascular extracellular volume fraction were independently prognostic in the preoperative model, and kurtosis of volume transfer constant and extravascular extracellular volume fraction were independently prognostic in the postoperative model. For progression-free survival, independent prognostic factors were minimum and fifth percentile values of volume transfer constant and kurtosis of extravascular extracellular volume fraction in the preoperative model and kurtosis of extravascular extracellular volume fraction in the postoperative model. The performance of preoperative models for progression-free survival was significantly improved when minimum or fifth percentile values of volume transfer constant and kurtosis of extravascular extracellular volume fraction were added.

CONCLUSIONS: Higher volume transfer constant and extravascular extracellular volume fraction values are associated with worse prognosis, and dynamic contrast-enhanced MR imaging may have added prognostic value in combination with preoperative clinical parameters, especially in predicting progression-free survival.

ABBREVIATIONS: $\mathrm{DCE}=$ dynamic contrast-enhanced; EGFR $=$ epidermal growth factor receptor; $\mathrm{KPS}=$ Karnofsky performance scale; $K^{\text {trans }}=$ volume transfer constant; MGMT = O6-methylguanine-DNA methyltransferase; $\mathrm{OS}=$ overall survival; $\mathrm{p}=$ percentile; $\mathrm{PFS}=$ progression-free survival; $\mathrm{v}_{\mathrm{e}}=$ extravascular extracellular volume fraction; $v_{p}=$ plasma volume fraction

G lioblastoma is the most common primary brain malignancy and its prognosis is dismal. ${ }^{1}$ Although the median survival time is approximately 14 months, occasional long-term survival and significant response to therapy have been reported in a subset of patients. ${ }^{2,3}$ Many investigations have been conducted to eluci-

Received January 20, 2015; accepted after revision April 20.

From the Departments of Radiology and Research Institute of Radiological Science (Y.S.C., S.-K.L., S.S.A.), Neurosurgery (J.H.C., S.-G.K., E.H.K.), Pathology (S.H.K.), and Ophthalmology (T.H.R.), Yonsei University College of Medicine, Seoul, Korea; and Department of Policy Research Affairs (D.W.K.), National Health Insurance Service Ilsan Hospital, Goyang, Gyeonggi-do, Korea. date the prognostic factors of glioblastoma, including clinical factors such as age, Karnofsky performance scale (KPS), and extent of tumor resection. ${ }^{4,5}$ Molecular and genetic biomarkers of glioblastoma, including O6-methylguanine-DNA methyltransferase (MGMT) promoter methylation, epidermal growth factor receptor (EGFR), p53, and Ki-67 index, are also emerging prognostic

Please address correspondence to Sung Soo Ahn, MD, PhD, Department of Radiology, College of Medicine, Yonsei University, 50 Yonsei-ro, Seodaemun-gu, Seoul 120-752, Korea; e-mail: SUNGSOO@yuhs.ac

三 Indicates article with supplemental on-line tables.

http://dx.doi.org/10.3174/ajnr.A4449 
factors predicting the biologic behavior of tumors. ${ }^{6-10}$ However, profiles of molecular biomarkers can only be obtained by invasive procedures such as biopsy or resection. Thus, MR imaging has been actively applied as a noninvasive tool for prognosis prediction and diagnosis and evaluation of treatment response; conventional imaging findings, such as edema, necrosis, or tumor size, have been known to be related to prognosis. ${ }^{5,11-14}$ Advanced MR imaging techniques have also been found to be of increasing utility in predicting prognosis of gliomas. For example, the lower apparent diffusion coefficient of diffusion-weighted imaging and higher relative cerebral blood volume of dynamic susceptibility contrast imaging have been reported to be correlated with worse prognosis in gliomas. ${ }^{15-18}$ Nevertheless, conflicting results were reported for the prognostic value of apparent diffusion coefficient. ${ }^{15,16,19}$ In addition, relative cerebral blood volume may involve biases of T1 effects and extravascular contrast leakage of tumor vessels and susceptibility artifacts, ${ }^{20}$ though T1 effects and extravascular contrast leakage can be limited by several techniques. $^{20-23}$

Using dynamic contrast-enhanced (DCE)-MR imaging, one can evaluate the blood-brain barrier by measuring quantitative permeability parameters such as volume transfer constant $\left(K^{\text {trans }}\right)$, extravascular extracellular volume fraction $\left(\mathrm{v}_{\mathrm{e}}\right)$, and plasma volume fraction $\left(\mathrm{v}_{\mathrm{p}}\right)$, which are quantitative metrics of vascular permeability, extravascular extracellular volume, and plasma volume, respectively. While $K^{\text {trans }}$ has been reported to increase with glioma grade, its prognostic value for overall survival (OS) remains controversial ${ }^{24,25}$ and its prognostic value for progression-fee survival (PFS) and added value to other previously known prognostic factors have not been investigated.

The purpose of our study was to investigate the association of DCE-MR imaging-derived parameters with OS and PFS in patients with glioblastoma, and their added prognostic value to preoperative clinical parameters and postoperative molecular biomarkers by using histogram analysis.

\section{MATERIALS AND METHODS}

This retrospective study was approved by the Severance Hospital of Yonsei University College of Medicine review board, which waived the requirement for informed consent.

\section{Subjects}

From October 2010 through April 2014, 98 consecutive patients with newly diagnosed glioblastoma, who underwent preoperative DCE-MR imaging, were reviewed. All patients were treated according to the standard regimen consisting of an operation and postoperative involved-field radiation therapy with temozolomide, as described elsewhere. ${ }^{26}$ Inclusion criteria were the following: 1) pure glioblastoma without other cell components mentioned in the pathologic report; 2) available profile of molecular biomarkers reported postoperatively, including MGMT methylation, EGFR, p53, Ki-67 index, and isocitrate dehydrogenase $1 \mathrm{mu}-$ tation; and 3) patients who underwent either total, subtotal, or partial resection of tumor. Exclusion criteria were the following: 1) glioblastoma mixed with other cell components, such as an oligodendroglial component, or any specific subtype of glioblastoma such as giant cell glioblastoma or gliosarcoma $(n=22) ; 2)$ positive or unknown isocitrate dehydrogenase 1 mutation status $(n=10)$; and 3 ) patients who did not undergo an operation ( $n=$ 2 ) or underwent biopsy only $(n=3)$. We excluded glioblastomas with heterogeneous cellular components and isocitrate dehydrogenase 1 mutations, to exclude confounding factors that affect prognosis $^{27,28}$ and to conduct accurate survival analysis with pure primary glioblastoma only. Therefore, 61 patients were enrolled in this study (male/female ratio $=32: 29 ; 63.0 \pm 9.8$ years of age).

\section{Image Acquisition}

Preoperative MR imaging was performed by using 3T imaging (Achieva; Philips Healthcare, Best, the Netherlands) and an 8 -channel sensitivity encoding head coil. The preoperative MR imaging protocol included conventional sequences consisting of T1-weighted imaging (TR, $2000 \mathrm{~ms}$; TE, $10 \mathrm{~ms}$; FOV, $240 \mathrm{~mm}$; section thickness, $5 \mathrm{~mm}$; and matrix, $256 \times 256$ ), T2-weighted imaging (TR, $3000 \mathrm{~ms}$; TE, $80 \mathrm{~ms}$; FOV, $240 \mathrm{~mm}$; section thickness, $5 \mathrm{~mm}$; and matrix, $256 \times 256$ ), and fluid-attenuated inversion recovery imaging (TR, 10,000 ms; TE, 125 ms; FOV, 240 mm; section thickness, $5 \mathrm{~mm}$; and matrix, $256 \times 256$ ). For DCE-MR imaging, 60 dynamic phases of DCE T1-weighted images were acquired with the following parameters: TR, $6.3 \mathrm{~ms}$; TE, $3.1 \mathrm{~ms}$; FOV, 240 mm; matrix, $192 \times 192 \mathrm{~mm}$; section thickness, $3 \mathrm{~mm}$; and flip angle, $15^{\circ}$. After acquiring the fifth phase of image volume, gadolinium-based contrast $(0.1-\mathrm{mL} / \mathrm{kg}$ gadobutrol, Gadavist; Bayer Schering Pharma, Berlin, Germany) was injected at a rate of $3 \mathrm{~mL} / \mathrm{s}$. The total acquisition time for DCE-MR imaging was 6 minutes 18 seconds.

\section{DCE-MR Imaging Analysis}

DCE-MR imaging data were moved to a personal computer and processed off-line with commercial software (nordicICE; NordicNeuroLab, Bergen, Norway), which is based on the pharmacokinetic model established by Tofts et al. ${ }^{29}$ DCE-MR imaging parameter maps of $K^{\text {trans }}, \mathrm{v}_{\mathrm{e}}$, and $\mathrm{v}_{\mathrm{p}}$ were generated after calibration of motion correction and determination of arterial input function, which was calculated from 5 spots on the M1 segment ipsilateral to the tumor. The baseline $\mathrm{T} 1$ value was fixed at $1000 \mathrm{~ms}$ in this study. ${ }^{30-33}$ The ROI was drawn by 1 neuroradiologist (Y.S.C.) and confirmed by another neuroradiologist (S.S.A.) on the basis of the last phase of DCE-MR images to contain the entire enhancing tumor volume by using a semiautomatic method by thresholding of signal intensity. The histogram parameters consisting of mean, minimum, fifth percentile (p5), and 25th (p25), 50th (p50), 75th (p75), and 95th (p95) percentiles and maximum values, skewness, and kurtosis of $K^{\text {trans }}, \mathrm{v}_{\mathrm{e}}$, and $\mathrm{v}_{\mathrm{p}}$, were calculated from ROIs overlaid on DCE-MR imaging parameter maps.

\section{Other Prognostic Parameters}

We recorded the following clinical parameters: age, sex, and preoperative KPS. The extent of tumor resection was classified as total, subtotal, or partial on the basis of the surgeon's intraoperative impression in conjunction with examination of postoperative images, with "subtotal resection" meaning $<100 \%$ but $\geq 75 \%$ tumor removal and "partial resection" meaning $<75 \%$ gross tumor removal. In addition, tumor descriptors on conventional MR images were determined by consensus of 2 neuroradiologists 
(Y.S.C. and S.S.A., with 2 and 5 years of experience in brain MR imaging, respectively) and were considered preoperative parameters in subsequent analyses, which consisted of enhancing tumor volume, degree of edema, and the presence of noncontrast-enhancing tumor. Enhancing tumor volume was automatically calculated from ROIs drawn for DCE-MR imaging analysis. Edema was scored by using the maximum distance of edema from the tumor margin as 0 (not apparent), if $<1 \mathrm{~cm} ; 1$ (mild to moderate), if $>1$ and $<2 \mathrm{~cm}$; and 2 (severe), if $>2 \mathrm{~cm}$. Non-contrast-enhancing tumor was defined as intermediate T2 signal intensity (less than the intensity of CSF) that is associated with mass effect and architectural distortion. Non-contrast-enhancing tumor was visually assessed and classified as positive if non-contrast-enhancing tumor volume was $>25 \%$ of enhancing tumor volume, or negative otherwise.

We also recorded postoperatively obtained profiles of molecular biomarkers, including MGMT methylation, EGFR, p53, and Ki-67 index.

\section{Definition of Survival Time}

"Overall survival" was defined as the time from diagnosis to death or last follow-up date when the patient was known to be alive. "Progression-free survival" was defined as the time from diagnosis to tumor progression, recurrence, death, or the last follow-up date in which the patient showed no disease progression. The definition and date of tumor progression were based on the Response Assessment in Neuro-Oncology criteria: in brief, 1) the first follow-up date showing $\geq 25 \%$ increase in an enhancing lesion or an increase in a nonenhancing lesion inside the radiation field, which increased in size at a consecutive MR imaging follow-up or was pathologically proved to be a recurrent tumor; 2 ) the initial follow-up date with a newly appearing enhancing lesion outside the radiation field; 3 ) the date showing clinical deterioration secondary to disease; and 4) the date of death for patients who died and did not meet the above criteria. The date of tumor progression on MR imaging was determined by consensus of 2 neuroradiologists (Y.S.C. and S.S.A.).

\section{Statistical Analysis}

Univariate analysis by using the Cox proportional hazard analysis was performed for both OS and PFS, with the histogram parameters of DCE-MR imaging $\left(K^{\text {trans }}, \mathrm{v}_{\mathrm{e}}\right.$, and $\left.\mathrm{v}_{\mathrm{p}}\right)$, clinical parameters (age, sex, KPS, extent of resection), tumor descriptors (eg, enhancing tumor volume, edema, non-contrast-enhancing tumor), and postoperative molecular biomarkers (MGMT methylation, EGFR overexpression, p53, and Ki-67 index). Continuous variables, including DCE-MR imaging parameters, and categoric variables of $>3$ categories were dichotomized by using the $\mathrm{K}$ adaptive partitioning algorithm to identify the most significant cutoff points affecting OS and PFS. ${ }^{34,35}$

Multivariate analysis by using the Cox regression model was performed with significant factors on univariate analysis to build prognostic models predicting OS and PFS. The prognostic models were built in 2 ways each for OS and PFS to investigate the added value of DCE-MR imaging in preoperative and postoperative settings: preoperative models with clinical and DCE-MR imaging
Table 1: Patient characteristics $(n=61)$

\begin{tabular}{lc}
\hline \multicolumn{1}{c}{ Variables } & Mean (SD) or No. (\%) \\
\hline Age (year) $)^{a}$ & $63.0(9.8)$ \\
Sex & \\
Male & $32(52.5 \%)$ \\
Female & $29(47.5 \%)$ \\
Karnofsky performance scale ${ }^{\mathrm{a}}$ & $72.1(12.1)$ \\
Enhancing tumor volume $\left(\mathrm{cm}^{3}\right)^{\mathrm{a}}$ & $23.5(19.1)$ \\
Extent of resection & \\
Total & $28(45.9 \%)$ \\
Subtotal or partial & $33(54.1 \%)$ \\
Edema & \\
None & $9(14.8 \%)$ \\
Mild-to-moderate & $15(24.6 \%)$ \\
Severe & $37(60.6 \%)$ \\
Non-contrast-enhancing tumor & \\
Negative & $26(42.6 \%)$ \\
Positive & $35(57.4 \%)$ \\
MGMT & \\
Unmethylated & $38(62.3 \%)$ \\
Methylated & $23(37.7 \%)$ \\
EGFR & \\
0 & $10(16.4 \%)$ \\
$1+$ & $3(4.9 \%)$ \\
$2+$ & $15(24.6 \%)$ \\
$3+$ & $33(54.1 \%)$ \\
p53 & $17.5(28.0)$ \\
Ki-67 & $23.4(19.0)$ \\
\hline
\end{tabular}

${ }^{a}$ Indicates mean and SD in parentheses.

parameters and postoperative models with clinical and DCE-MR imaging parameters and molecular biomarkers.

After multivariate analysis, performance of each prognostic model was evaluated by using the Harrell concordance index (Cindex). A C-index value of 0.5 indicates random prediction, and 1.0 indicates perfect prediction. C-indexes were compared between the models, with and without DCE-MR imaging parameters, according to the Newson method. ${ }^{36,37}$ To avoid overestimation of the performance of prognostic models, we used the jacknife data resampling technique in calculating $\mathrm{C}$-indexes and their $95 \%$ confidence intervals. In addition, multicollinearity was checked by calculating the variable inflation factor of each variable included in the models. A variable inflation factor of $>2.5$ was considered multicollinearity, influencing the estimated $\beta$ power. Variable inflation factors of all variables included in prognostic models were $<2.0$. Statistical analyses were conducted with the Stata software package (Version 12.1; StataCorp, College Station, Texas), and a $P$ value $<.05$ was considered statistically significant.

\section{RESULTS}

Characteristics of the 61 enrolled patients are summarized in Table 1 . The locations of the tumors were as follows: frontal ( $n=$ $19)$, temporal $(n=18)$, parietal $(n=15)$, occipital lobe $(n=2)$, basal ganglia $(n=1)$, thalamus $(n=4)$, and corpus callosum $(n=$ 2 ). Thirteen patients had tumors encasing or abutting the ipsilateral M1 segment. Among the 61 patients, 29 deaths and 37 tumor progressions occurred. The restricted mean and standard error of overall survival time was $552.6 \pm 40.6$ days, and the restricted mean and standard error of progression-free survival time was $359.7 \pm 31.2$ days. The follow-up for those still alive ranged from 24 to 893 days.

AJNR Am J Neuroradiol 36:2235-41 Dec 2015 www.ajnr.org 
$\mathrm{K}^{\text {trans }} \_\mathrm{p} 5$ and overall survival
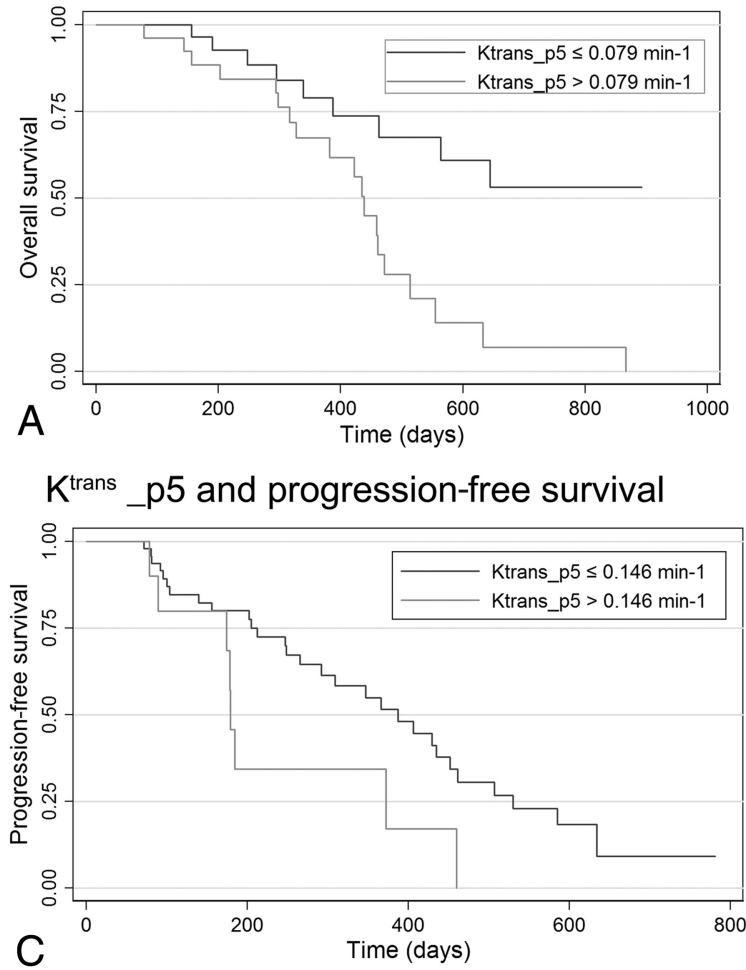

$\mathrm{v}_{\mathrm{e}} \_$p50 and overall survival

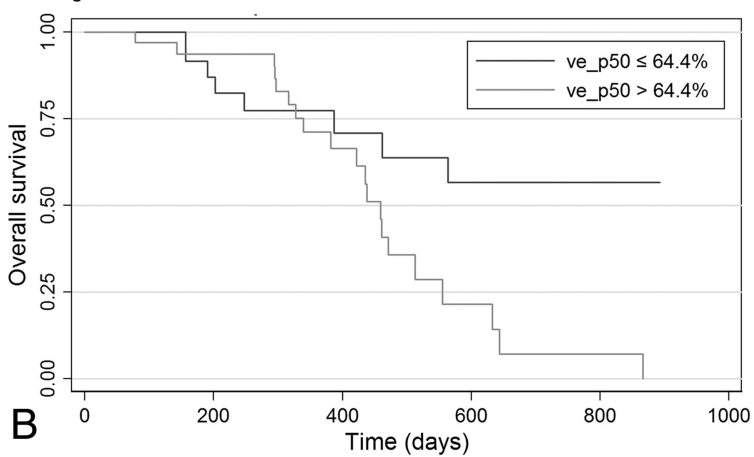

$\mathrm{v}_{\mathrm{e}} \_$p50 and progression-free survival

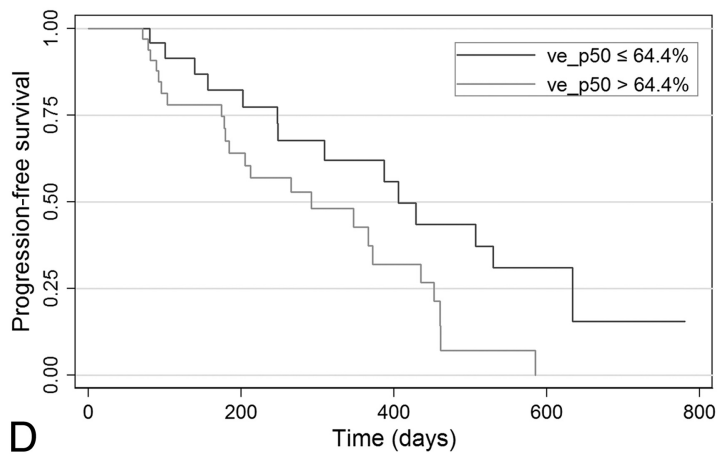

FIG 1. Kaplan-Meier analysis of overall survival according to $K^{\text {trans }}(A)$ and $\mathrm{v}_{\mathrm{e}}(B)$, and progression-free survival according to $K^{\text {trans }}(C)$ and $\mathrm{v}_{\mathrm{e}}(D)$.

Table 2: Preoperative and postoperative prognostic models for overall survival

\begin{tabular}{|c|c|c|c|c|c|c|c|c|c|c|}
\hline \multirow[b]{2}{*}{ Parameters } & \multicolumn{2}{|c|}{ Model $1^{a}$} & \multicolumn{2}{|c|}{ Model $2^{a}$} & \multicolumn{2}{|l|}{ Model $3^{a}$} & \multicolumn{2}{|c|}{ Model $4^{b}$} & \multicolumn{2}{|c|}{ Model $5^{b}$} \\
\hline & HR (95\% Cl) & $P$ Value & HR & $P$ Value & HR & $P$ Value & HR & $P$ Value & HR & $P$ Value \\
\hline $\begin{array}{l}\text { Enhancing tumor } \\
\text { volume }\end{array}$ & $1.38(0.53-3.60)$ & .509 & $2.49(1.11-5.58)$ & .027 & $1.09(0.43-2.78)$ & .855 & $0.80(0.31-2.05)$ & .643 & $0.94(0.38-2.37)$ & .904 \\
\hline Age & 3.47 (1.42-8.49) & .007 & 2.49 (1.00-6.19) & .049 & $1.55(1.25-8.26)$ & .015 & $2.91(1.20-7.04)$ & .018 & $2.66(1.08-6.58)$ & .034 \\
\hline KPS & $2.86(1.15-7.15)$ & .024 & $2.87(1.13-7.24)$ & .026 & $2.54(1.02-6.33)$ & .046 & $1.09(0.34-3.47)$ & .888 & $1.12(0.35-3.63)$ & .845 \\
\hline$K^{\text {trans }} \_\mathrm{p} 5$ & $2.82(1.04-7.70)$ & .043 & - & & $2.93(1.64-15.74)$ & .005 & - & & - & \\
\hline $\mathrm{v}_{\mathrm{e} \_}$kurtosis & - & & 7.57 (1.49-38.51) & .015 & 21.90 (3.79-145.91) & .001 & - & & 5.65 (1.13-28.37) & .035 \\
\hline$K^{\text {trans }}$ kurtosis & - & & - & & - & & 4.99 (1.05-23.78) & .044 & - & \\
\hline MGMT & - & & - & & - & & 7.80 (1.96-31.04) & .004 & 6.82 (1.77-26.31) & .005 \\
\hline EGFR & - & & - & & - & & 4.25 (1.44-12.61) & .009 & 3.65 (1.21-10.95) & .021 \\
\hline
\end{tabular}

Note:- - indicates not applicable; HR, hazard ratio.

${ }^{a}$ Preoperative models.

a Postoperative models.

\section{Univariate Analysis for Overall Survival}

Histogram analysis of DCE-MR imaging parameters (On-line Table 1) revealed that high $K^{\text {trans }}$ and $\mathrm{v}_{\mathrm{e}}$ values showed a trend toward worse OS and that this trend was statistically significant in kurtosis, minimum, p5, p25, and p50 values of $K^{\text {trans }}(P$ values $=$ $.016, .007, .004, .012$, and .023 , respectively) and kurtosis, mean, $\mathrm{p} 5, \mathrm{p} 25, \mathrm{p} 50, \mathrm{p} 75$, and $\mathrm{p} 95$ values of $\mathrm{v}_{\mathrm{e}}(P$ values $=.005, .034, .005$, $.040, .027, .041$, and .02, respectively). Histogram parameters of $\mathrm{v}_{\mathrm{p}}$ showed no significant correlation with OS. Kaplan-Meier curves of representative prognostic parameters of $K^{\text {trans }}$ and $v_{\mathrm{e}}$ are depicted in Fig 1. Among other parameters, older than 68 years of age, KPS of $<70$, enhancing tumor volume of $>30 \mathrm{~cm}^{2}$, MGMT unmethylation, and EGFR $>2+$ were associated with worse OS (On-line Table 2).

\section{Multivariate Analysis for Overall Survival}

In multivariate analysis for preoperative prognostic models with clinical and DCE-MR imaging parameters, $\mathrm{p} 5$ value of $K^{\text {trans }}$ and kurtosis of $\mathrm{v}_{\mathrm{e}}$ were independently prognostic for OS in addition to age and KPS, and these 2 parameters remained independently prognostic when entered into multivariate analysis at the same time (Table 2). In multivariate analysis for postoperative prognostic models with molecular biomarkers added, kurtosis of $K^{\text {trans }}$ and $\mathrm{v}_{\mathrm{e}}$ were independently prognostic for OS, and these 2 parameters became insignificant when both were entered into multivariate analysis at the same time.

\section{Univariate Analysis for Progression-Free Survival}

Histogram analysis of DCE-MR imaging parameters (On-line Table 1) revealed that high $K^{\text {trans }}$ and $\mathrm{v}_{\mathrm{e}}$ values showed a trend toward worse PFS and that this trend was statistically significant in kurtosis, minimum, p5, and p25 values of $K^{\text {trans }}(P$ value $=$ $.033, .008, .029$, and .043, respectively) and kurtosis, p5, p50, and p95 values of $\mathrm{v}_{\mathrm{e}}(P$ value $=.004, .046,0031$, and .029 , respectively). Histogram parameters of $v_{p}$ showed no significant corre- 
Table 3: Preoperative and postoperative prognostic models for progression-free survival

\begin{tabular}{|c|c|c|c|c|c|c|c|c|c|c|c|c|}
\hline \multirow[b]{2}{*}{ Parameters } & \multicolumn{2}{|c|}{ Model $1^{\mathrm{a}}$} & \multicolumn{2}{|c|}{ Model $2^{\mathrm{a}}$} & \multicolumn{2}{|c|}{ Model $3^{a}$} & \multicolumn{2}{|c|}{ Model $4^{a}$} & \multicolumn{2}{|c|}{ Model $5^{a}$} & \multicolumn{2}{|c|}{ Model $6^{\mathrm{b}}$} \\
\hline & HR & $P$ Value & HR & $P$ Value & HR & $P$ Value & HR & $P$ Value & HR & $P$ Value & HR & $P$ Value \\
\hline $\begin{array}{l}\text { Enhancing tumor } \\
\text { volume }\end{array}$ & $2.9(1.4-6.0)$ & .005 & $1.9(0.9-4.0)$ & .105 & $2.4(1.1-5.0)$ & .023 & $3.1(1.5-6.7)$ & .003 & $1.8(0.8-3.9)$ & .135 & $1.4(0.6-3.2)$ & .423 \\
\hline Age & $2.4(1.2-4.8)$ & .015 & $3.1(1.4-6.6)$ & .004 & $2.4(1.1-4.9)$ & .020 & $2.5(1.2-5.2)$ & .011 & $3.4(1.6-7.6)$ & .002 & $2.4(1.1-4.9)$ & .020 \\
\hline$K^{\text {trans }} \min$ & $2.8(1.4-5.6)$ & .004 & - & & - & & $3.3(1.6-6.7)$ & .001 & - & & - & \\
\hline$K^{\text {trans }} \mathrm{p} 5$ & - & & $2.9(1.2-7.2)$ & .020 & - & & - & & $4.0(1.5-10.4)$ & .004 & - & \\
\hline $\mathrm{v}_{\mathrm{e}}$ kurtosis & - & & - & & $4.4(1.7-11.3)$ & .002 & $5.7(2.2-15.2)$ & .000 & $6.0(2.2-16.3)$ & .000 & $5.3(2.0-14.0)$ & .001 \\
\hline MGMT & - & & - & & - & & - & & - & & $3.1(1.3-7.4)$ & .012 \\
\hline
\end{tabular}

Note:- - indicates that the model doesn't have the corresponding factor as a covacriate; HR, hazard ratio.

a Preoperative models.

b Postoperative model.

lation with PFS. Kaplan-Meier curves of representative prognostic parameters of $K^{\text {trans }}$ and $v_{\mathrm{e}}$ are depicted in Fig 1 . Among other parameters, age older than 68 years, enhancing tumor volume $>30 \mathrm{~cm}^{3}$, and MGMT unmethylation were associated with worse PFS (On-line Table 2).

\section{Multivariate Analysis for Progression-Free Survival}

In multivariate analysis for preoperative prognostic models with clinical and DCE-MR imaging parameters, minimum and p5 of $K^{\text {trans }}$ and kurtosis of $\mathrm{v}_{\mathrm{e}}$ were independently prognostic for PFS in addition to age, and these DCE-MR imaging parameters remained independently prognostic when combined and entered into the multivariate analysis (Table 3 ). In multivariate analysis for postoperative prognostic models with molecular biomarkers added, only kurtosis of $\mathrm{v}_{\mathrm{e}}$ remained independently prognostic for PFS.

\section{Comparison of the Performance of the Prognostic Models} Comparisons of the performance of the prognostic models are summarized in On-line Table 3. The C-indexes ranged from 0.75 to 0.82 in prognostic models for OS, indicating good performance, and were higher in models with DCE-MR imaging parameters than in those without, though it was not statistically significant $(P>.05)$. The $\mathrm{C}$-indexes ranged from 0.70 to 0.74 in prognostic models for PFS and were higher in models with DCE-MR imaging parameters than in those without. Performance of the models appeared to be significantly improved when kurtosis of $\mathrm{v}_{\mathrm{e}}$, combined with either minimum or $\mathrm{p} 5$ of $K^{\text {trans }}$, was added into the preoperative models for PFS ( $P$ values were .034 and .046 for models with kurtosis of $\mathrm{v}_{\mathrm{e}}+$ minimum of $K^{\text {trans }}$, and kurtosis of $\mathrm{v}_{\mathrm{e}}+\mathrm{p} 5$ of $K^{\text {trans }}$, respectively).

\section{DISCUSSION}

We investigated the prognostic value of DCE-MR imaging in predicting OS and PFS and its added value to preoperative clinical parameters and postoperative molecular biomarkers in patients with glioblastoma. Higher cumulative histogram parameters and higher kurtosis of $K^{\text {trans }}$ and $\mathrm{v}_{\mathrm{e}}$ had a trend toward worse OS and PFS with statistical significance, which means that tumors having relatively higher frequency and peaks at higher $\mathrm{v}_{\mathrm{e}}$ and $K^{\text {trans }}$ values were correlated with worse prognosis.

The C-indexes were higher in models with either $K^{\text {trans }}$ or $\mathrm{v}_{\mathrm{e}}$ or both added than in models without DCE-MR imaging parameters, though the difference in C-indexes was statistically significant only in the preoperative models for PFS. Our results imply that DCE-MR imaging may have added prognostic value in combination with preoperative clinical parameters, especially in predicting PFS. However, we carefully suggest that the added prognostic value of DCE-MR imaging in combination with postoperative molecular biomarkers is uncertain. In our opinion, the small sample size and the small number of deaths and disease progression that occurred in our study cohort are primarily responsible for the lack of significant added value of DCE-MR imaging in the prognostic models. Another possible explanation is that DCE-MR imaging parameters would be less likely to show added prognostic value in combination with molecular biomarkers in postoperative models if correlation between DCE-MR imaging parameters and molecular biomarkers is one of the mechanisms by which DCE-MR imaging parameters exhibit prognostic value. Thus, further investigation with a larger cohort and analysis of biomarkers is necessary.

The $K^{\text {trans }}$ value reflects vascular permeability. In theory, tumor aggressiveness increases in tumors with higher $K^{\text {trans }}$ value, probably due to increased neoangiogenesis and vascular permeability required for tumor growth, ${ }^{38}$ by which the correlation between higher $K^{\text {trans }}$ value and worse prognosis is expected, as seen in our results. Nonetheless, the relationship between $K^{\text {trans }}$ and the prognosis of glioblastoma has been controversial. ${ }^{24,25,39}$ Mills et $\mathrm{al}^{24}$ reported that higher $K^{\text {trans }}$ was correlated with good overall survival in glioblastoma. In contrast, Awasthi et $\mathrm{al}^{40}$ reported the correlation between higher vascular permeability ( $K^{\text {trans }}$ and $v_{\mathrm{e}}$ ) and higher expression of matrix metalloproteinases, which has been associated with poor survival in glioblastoma. Nguyen et $\mathrm{al}^{25}$ reported that high $K^{\text {trans }}$ and $\mathrm{v}_{\mathrm{p}}$ values were associated with poor overall survival of high-grade glioma, while $v_{p}$ values were not significantly correlated with prognosis in our study. These conflicting results might be due to the enrollment of heterogeneous gliomas of various grades or with the oligodendroglial component, different methods of ROI drawing, and different effects of covariates affecting survival such as age, KPS, extent of tumor resection, edema, or necrosis.

$\mathrm{V}_{\mathrm{e}}$ is a quantitative metric of extravascular extracellular space volume on DCE-MR imaging and is considered an index of tumor necrosis. ${ }^{41}$ The correlation between higher $\mathrm{v}_{\mathrm{e}}$ and worse prognosis indicates that tumors with higher necrotic portions have worse prognoses, reflecting microscopic levels of necrosis undetectable on conventional MR imaging, though we excluded the gross necrotic portion and included only enhancing tumor volume in ROIs. This result agrees with a previous study that reported a positive correlation between $\mathrm{v}_{\mathrm{e}}$ value and matrix met- 
alloproteinases, an index reflecting cellular proliferation and invasion of tumors. ${ }^{40}$

The $\mathrm{v}_{\mathrm{p}}$ value reflects vascular volume fraction on DCE-MR imaging. However, no parameter of $\mathrm{v}_{\mathrm{p}}$ showed significant correlation with OS or PFS in our study, whereas previous studies with dynamic susceptibility contrast imaging suggested that increased relative cerebral blood volume is related to tumor grade, aggressiveness, and OS. ${ }^{42-45}$ In our opinion, these conflicting results for $\mathrm{v}_{\mathrm{p}}$ might be partially attributed to the limited accuracy of $\mathrm{v}_{\mathrm{p}}$ in a temporal resolution of $>2$ seconds. Previous studies recommended a temporal resolution of approximately 2 seconds or faster if plasma flow is to be estimated, ${ }^{46-48}$ and our measurement of $\mathrm{v}_{\mathrm{p}}$ might be inaccurate because we used a temporal resolution of 6 seconds. Nonetheless, a previous study with DCE-MR imaging reported $\mathrm{v}_{\mathrm{p}}$ as a prognostic parameter ${ }^{25}$ and suggested that conflicting results may also be related to differences in DCE-MR imaging protocol and methods for calculating arterial input function and ROI selection.

As far as we know, our study is the first investigation of the prognostic value of DCE-MR imaging with the largest and most homogeneous cohort of glioblastomas. Another strong point of our study is the semiautomatic drawing of ROIs with thresholds containing the entire enhancing tumor volume for histogram analysis of DCE parameters, because visually assessing several "hot spots" and not containing the entire enhancing tumor might be subjective and fail to reflect the characteristics of entire tumor. Additionally, we dichotomized the histogram parameters of $K^{\text {trans }}$ and $\mathrm{v}_{\mathrm{e}}$ with the most significant cutoff values affecting survival, which were identified by the K-adaptive partitioning algorithm. The trade-off of this method is that extreme cutoff values can be selected causing uneven dichotomization. For example, tumors with a kurtosis of $\mathrm{v}_{\mathrm{e}}$ of $>50.3 \%$ occupied only $6.6 \%$ of the entire cohort. Similarly, tumors with a kurtosis of $K^{\text {trans }}$ of $>0.042$ minutes $^{-1}$ and kurtosis of $\mathrm{v}_{\mathrm{e}}$ of $>27.8 \%$ occupied $13.1 \%$ and $11.5 \%$, respectively. These extreme cutoff values and subsequent uneven dichotomization may be more useful as adjunct prognostic parameters to other prognostic parameters, rather than as a single prognostic parameter alone.

There are several limitations in our study. First is a lack of generalizability and standardization of DCE-MR imaging-derived parameters, which can be affected by postprocessing software, calibration for T1 relaxation, and the protocol of DCE-MR imaging. Hence, any specific cutoff values of $K^{\text {trans }}$ or $\mathrm{v}_{\mathrm{e}}$ in this study cannot be generally used, and this study suggests only the potential for the added prognostic value of DCE-MR imaging. In addition, the repeatability of DCE-MR imaging parameters has been a major problem, though this can be reduced with improved methodologies for data acquisition and postprocessing. ${ }^{30,49-51}$ Also, arterial input function calculation might have been inaccurate, especially in the 13 patients with tumors encasing the ipsilateral M1 segment. Second, the number of deaths and disease progressions that occurred in our study cohort might be too small to show the statistically significant added value of DCE-MR imaging in the prognostic models, except in preoperative models for PFS.

\section{CONCLUSIONS}

Higher $K^{\text {trans }}$ and $\mathrm{v}_{\mathrm{e}}$ values were associated with worse prognosis, and DCE-MR imaging may have added prognostic value to preoperative clinical imaging parameters, especially in predicting progression-free survival.

\section{REFERENCES}

1. Van Meir EG, Hadjipanayis CG, Norden AD, et al. Exciting new advances in neuro-oncology: the avenue to a cure for malignant glioma. CA Cancer J Clin 2010;60:166-93 CrossRef Medline

2. Zikou AK, Alexiou GA, Kosta P, et al. Diffusion tensor and dynamic susceptibility contrast MRI in glioblastoma. Clin Neurol Neurosurg 2012;114:607-12 CrossRef Medline

3. Liu Y, Shete S, Etzel CJ, et al. Polymorphisms of LIG4, BTBD2, HMGA2, and RTEL1 genes involved in the double-strand break repair pathway predict glioblastoma survival. J Clin Oncol 2010;28: 2467-74 CrossRef Medline

4. Stark AM, Stepper W, Mehdorn HM. Outcome evaluation in glioblastoma patients using different ranking scores: KPS, GOS, mRS and MRC. Eur J Cancer Care (Engl) 2010;19:39-44 CrossRef Medline

5. Lacroix M, Abi-Said D, Fourney DR, et al. A multivariate analysis of 416 patients with glioblastoma multiforme: prognosis, extent of resection, and survival. J Neurosurg 2001;95:190-98 CrossRef Medline

6. Mellinghoff IK, Wang MY, Vivanco I, et al. Molecular determinants of the response of glioblastomas to EGFR kinase inhibitors. $N$ Engl J Med 2005;353:2012-24 CrossRef Medline

7. Hegi ME, Diserens AC, Gorlia T, et al. MGMT gene silencing and benefit from temozolomide in glioblastoma. N Engl J Med 2005;352: 997-1003 CrossRef Medline

8. Simmons ML, Lamborn KR, Takahashi M, et al. Analysis of complex relationships between age, p53, epidermal growth factor receptor, and survival in glioblastoma patients. Cancer Res 2001;61:1122-28 Medline

9. Shiraishi S, Tada K, Nakamura H, et al. Influence of p53 mutations on prognosis of patients with glioblastoma. Cancer 2002;95:249-57 CrossRef Medline

10. Shinojima N, Tada K, Shiraishi S, et al. Prognostic value of epidermal growth factor receptor in patients with glioblastoma multiforme. Cancer Res 2003;63:6962-70 Medline

11. Pope WB, Sayre J, Perlina A, et al. MR imaging correlates of survival in patients with high-grade gliomas. AJNR Am J Neuroradiol 2005; 26:2466-74 Medline

12. Chaichana KL, Kosztowski T, Niranjan A, et al. Prognostic significance of contrast-enhancing anaplastic astrocytomas in adults. J Neurosurg 2010;113:286-92 CrossRef Medline

13. Tynninen $\mathrm{O}$, Aronen HJ, Ruhala M, et al. MRI enhancement and microvascular density in gliomas: correlation with tumor cell proliferation. Invest Radiol 1999;34:427 CrossRef Medline

14. Hammoud MA, Sawaya R, Shi W, et al. Prognostic significance of preoperative MRI scans in glioblastoma multiforme. J Neurooncol 1996;27:65-73 CrossRef Medline

15. Higano S, Yun X, Kumabe T, et al. Malignant astrocytic tumors: clinical importance of apparent diffusion coefficient in prediction of grade and prognosis. Radiology 2006;241:839-46 CrossRef Medline

16. Oh J, Henry RG, Pirzkall A, et al. Survival analysis in patients with glioblastoma multiforme: predictive value of choline-to- $\mathrm{N}$-acetylaspartate index, apparent diffusion coefficient, and relative cerebral blood volume. J Magn Reson Imaging 2004;19:546-54 CrossRef Medline

17. Murakami R, Sugahara T, Nakamura H, et al. Malignant supratentorial astrocytoma treated with postoperative radiation therapy: prognostic value of pretreatment quantitative diffusion-weighted MR imaging. Radiology 2007;243:493-99 CrossRef Medline

18. Law M, Young RJ, Babb JS, et al. Gliomas: predicting time to progression or survival with cerebral blood volume measurements at 
dynamic susceptibility-weighted contrast-enhanced perfusion MR imaging. Radiology 2008;247:490-98 CrossRef Medline

19. Pope WB, Lai A, Mehta R, et al. Apparent diffusion coefficient histogram analysis stratifies progression-free survival in newly diagnosed bevacizumab-treated glioblastoma. AJNR Am J Neuroradiol 2011;32:882-89 CrossRef Medline

20. Boxerman J, Schmainda K, Weisskoff R. Relative cerebral blood volume maps corrected for contrast agent extravasation significantly correlate with glioma tumor grade, whereas uncorrected maps do not. AJNR Am J Neuroradiol 2006;27:859-67 Medline

21. Paulson ES, Schmainda KM. Comparison of dynamic susceptibilityweighted contrast-enhanced MR methods: recommendations for measuring relative cerebral blood volume in brain tumors. Radiology 2008;249:601-13 CrossRef Medline

22. Hu L, Baxter L, Pinnaduwage D, et al. Optimized preload leakagecorrection methods to improve the diagnostic accuracy of dynamic susceptibility-weighted contrast-enhanced perfusion MR imaging in posttreatment gliomas. AJNR Am J Neuroradiol 2010;31:40-48 CrossRef Medline

23. Boxerman J, Prah D, Paulson E, et al. The role of preload and leakage correction in gadolinium-based cerebral blood volume estimation determined by comparison with MION as a criterion standard. AJNR Am J Neuroradiol 2012;33:1081-87 CrossRef Medline

24. Mills SJ, Patankar TA, Haroon HA, et al. Do cerebral blood volume and contrast transfer coefficient predict prognosis in human glioma? AJNR Am J Neuroradiol 2006;27:853-58 Medline

25. Nguyen TB, Cron GO, Mercier JF, et al. Preoperative prognostic value of dynamic contrast-enhanced MRI-derived contrast transfer coefficient and plasma volume in patients with cerebral gliomas. AJNR Am J Neuroradiol 2015;36:63-69 CrossRef Medline

26. Kim YS, Kim SH, Cho J, et al. MGMT gene promoter methylation as a potent prognostic factor in glioblastoma treated with temozolomide-based chemoradiotherapy: a single-institution study. Int $J$ Radiat Oncol Biol Phys 2012;84:661-67 CrossRef Medline

27. Wang Y, Li S, Chen L, et al. Glioblastoma with an oligodendroglioma component: distinct clinical behavior, genetic alterations, and outcome. Neuro Oncol 2012;14:518-25 CrossRef Medline

28. Parsons DW, Jones S, Zhang X, et al. An integrated genomic analysis of human glioblastoma multiforme. Science 2008;321:1807-12 CrossRef Medline

29. Tofts PS, Brix G, Buckley DL, et al. Estimating kinetic parameters from dynamic contrast-enhanced T (1)-weighted MRI of a diffusable tracer: standardized quantities and symbols. J Magn Reson Imaging 1999;10:223-32 CrossRef Medline

30. Haacke EM, Filleti CL, Gattu R, et al. New algorithm for quantifying vascular changes in dynamic contrast-enhanced MRI independent of absolute T1 values. Magn Reson Med 2007;58:463-72 CrossRef Medline

31. Yun TJ, Park CK, Kim TM, et al. Glioblastoma treated with concurrent radiation therapy and temozolomide chemotherapy: differentiation of true progression from pseudoprogression with quantitative dynamic contrast-enhanced MR imaging. Radiology 2015;274: 830 - 40 CrossRef Medline

32. Jung SC, Yeom J, Kim JH, et al. Glioma: application of histogram analysis of pharmacokinetic parameters from T1-weighted dynamic contrast-enhanced MR imaging to tumor grading. AJNR Am J Neuroradiol 2014;35:1103-10 CrossRef Medline

33. Alcaide-Leon P, Pareto D, Martinez-Saez E, et al. Pixel-by-pixel comparison of volume transfer constant and estimates of cerebral blood volume from dynamic contrast-enhanced and dynamic susceptibility contrast-enhanced MR imaging in high-grade gliomas. AJNR Am J Neuroradiol 2015;36:871-76 CrossRef Medline

34. Kang HJ, Eo SH, Kim SC, et al. Increased number of metastatic lymph nodes in adenocarcinoma of the ampulla of Vater as a prog- nostic factor: a proposal of new nodal classification. Surgery 2014; 155:74-84 CrossRef Medline

35. Palumbo A, Avet-Loiseau H, Oliva $\mathrm{S}$, et al. Revised International Staging System for Multiple Myeloma: A Report From International Myeloma Working Group. J Clin Oncol 2015;33:2863-69 CrossRef Medline

36. Newson RB. Comparing the predictive powers of survival models using Harrell's C or Somers' D. Stata Journal 2010;10:339-58

37. Dolcetta-Capuzzo A, Villa V, Albarello L, et al. Gastroenteric neuroendocrine neoplasms classification: comparison of prognostic models. Cancer 2013;119:36-44 CrossRef Medline

38. Venkatasubramanian R, Arenas R, Henson M, et al. Mechanistic modelling of dynamic MRI data predicts that tumour heterogeneity decreases therapeutic response. Br J Cancer 2010;103:486-97 CrossRef Medline

39. Bonekamp D, Deike K, Wiestler B, et al. Association of overall survival in patients with newly diagnosed glioblastoma with contrastenhanced perfusion MRI: Comparison of intraindividually matched T1-and T2*-based bolus techniques. J Magn Reson Imaging 2015;42:87-96 CrossRef Medline

40. Awasthi R, Pandey CM, Sahoo P, et al. Dynamic contrast-enhanced magnetic resonance imaging-derived kep as a potential biomarker of matrix metalloproteinase 9 expression in patients with glioblastoma multiforme: a pilot study. J Comput Assist Tomogr 2012;36: 125-30 CrossRef Medline

41. Carmeliet P, Jain RK. Angiogenesis in cancer and other diseases. Nature 2000;407:249-57 CrossRef Medline

42. Law M, Oh S, Johnson G, et al. Perfusion magnetic resonance imaging predicts patient outcome as an adjunct to histopathology: a second reference standard in the surgical and nonsurgical treatment of low-grade gliomas. Neurosurgery 2006;58:1099-107; discussion 1099-107 CrossRef Medline

43. Caseiras GB, Chheang S, Babb J, et al. Relative cerebral blood volume measurements of low-grade gliomas predict patient outcome in a multi-institution setting. Eur J Radiol 2010;73:215-20 CrossRef Medline

44. Sugahara T, Korogi Y, Kochi M, et al. Correlation of MR imagingdetermined cerebral blood volume maps with histologic and angiographic determination of vascularity of gliomas. AJR Am J Roentgenol 1998;171:1479-86 CrossRef Medline

45. Law M, Yang S, Babb JS, et al. Comparison of cerebral blood volume and vascular permeability from dynamic susceptibility contrastenhanced perfusion MR imaging with glioma grade. AJNR Am J Neuroradiol 2004;25:746-55 Medline

46. Ingrisch M, Dietrich O, Attenberger UI, et al. Quantitative pulmonary perfusion magnetic resonance imaging: influence of temporal resolution and signal-to-noise ratio. Invest Radiol 2010;45:7-14 CrossRef Medline

47. Ingrisch $\mathrm{M}$, Sourbron S. Tracer-kinetic modeling of dynamic contrast-enhanced MRI and CT: a primer. J Pharmacokinet Pharmacodyn 2013;40:281-300 CrossRef Medline

48. Sourbron S. Technical aspects of MR perfusion. Eur J Radiol 2010; 76:304-13 CrossRef Medline

49. Ahearn T, Staff R, Redpath $\mathrm{T}$, et al. The effects of renal variation upon measurements of perfusion and leakage volume in breast tumours. Phys Med Boil 2004;49:2041-51 CrossRef Medline

50. Dale BM, Jesberger JA, Lewin JS, et al. Determining and optimizing the precision of quantitative measurements of perfusion from dynamic contrast enhanced MRI. J Magn Reson Imaging 2003;18: 575-84 CrossRef Medline

51. Galbraith SM, Lodge MA, Taylor NJ, et al. Reproducibility of dynamic contrast-enhanced MRI in human muscle and tumours: comparison of quantitative and semi-quantitative analysis. $N M R$ Biomed 2002;15:132-42 CrossRef Medline 